\title{
O PATRIMÔNIO INDUSTRIAL DE PORTO ALEGRE/RS
}

\author{
The Industrial Heritage of Porto Alegre/RS
}

\section{Sílvia Eidt Monteiro}

Graduada em Arquitetura e Urbanismo - UFSM (RS, Brasil). Mestre em Arquitetura e Urbanismo UNIRITTER/MACKENZIE. Especialista em Auditoria, Avaliações e Perícias de Engenharia - IPOG. Especialista em Projetos de Arquitetura e Urbanismo em Áreas de Interesse Cultural - Unyleya

\begin{abstract}
Resumo
Este artigo objetiva fomentar as discussões acerca da conservação e restauração do patrimônio edificado, com foco nas edificações de herança industrial, como forma de viabilizar a permanência destas grandes estruturas e vinculá-las a dinâmica das cidades contemporâneas. Para isso, apresenta-se o conceito de patrimônio industrial e o crescente interesse no tema, devido ao seu potencial articulador na requalificação de extensas áreas. Posteriormente, realiza-se o mapeamento e o diagnóstico do patrimônio industrial do IV Distrito de Porto Alegre/RS. São identificadas antigas fábricas de tecelagem, peças, móveis, medicamentos, produtos alimentícios, além de, cervejarias, moinhos e armazéns. Investiga-se o passado e o presente destas edificações. Observa-se que muitas já não existem ou estão em situação de abandono. Outras, sofrem reuso espontâneo ou tentativas formais de mesma finalidade. Sendo assim, é possível evidenciar a conjuntura atual do patrimônio industrial em Porto Alegre, os principais tipos de reuso, a qualidade das intervenções e as potencialidades não exploradas. Este trabalho é fruto da pesquisa da dissertação de título 'Requalificação Urbana e Patrimônio Industrial: estudo de intervenções em áreas de herança industrial', sob orientação do Prof. Dr. Luiz Antônio Bolcato Custódio, apresentada ao programa de Pós-Graduação - Mestrado em Arquitetura e Urbanismo da UniRitter / Mackenzie.
\end{abstract}

Palavras-chave: Patrimônio. Patrimônio Industrial. IV Distrito de Porto Alegre. Reuso.

\begin{abstract}
This paper aims to instigate discussions about the conservation and restoration of built heritage, focusing on constructions with an industrial past. Considering how to make possible the permanence of those massive structures and to link them to the dynamics of the contemporary cities. For this, the concept of industrial heritage and the growing interest in the theme are presented, due to its articulator potential in the requalification of extensive areas. Subsequently, is accomplished the mapping and diagnosis of the industrial heritage of the IV District of Porto Alegre/RS. Old factories of weaving, metal parts, furniture, medicines, food, as well as brewery, mills and ware houses area identified. It investigates the past and the present of these buildings and observe that many no longer exist or are in a situation of abandonment. Others suffer spontaneous reuse or formal attempts of the same purpose. Thus, it is possible to show the current conjuncture of the industrial heritage in Porto Alegre, the main types of reuse, the quality of interventions and unseen potentialities. This work is the result of the research for the dissertation titled 'Urban Rehabilitation and Industrial Heritage: study of interventions in areas of industrial heritage', under the guidance of Prof. PhD. Luiz Antônio Bolcato Custódio, presented to the Post Graduation Program Master in Architecture and Urbanism from UniRitter / Mackenzie.
\end{abstract}

Keywords: Heritage. Industrial Heritage. IV District of Porto Alegre. Reuse.

\section{Sumário}

1. Introdução; 2. O patrimônio industrial segundo a Carta de Nizhny Tagil; 3. A cidade de Porto Alegre e sua herança industrial; 3.1 Berta, 1873; 3.2 Pregos e Pontas de Paris, 1891; 3.3 Companhia Fiação e Tecidos Porto Alegrense FIATECI, 1891; 3.4 Cervejaria Bopp, 1910; 3.5. Moinho Rio-Grandense, 1915; 3.6 Móveis Gerdau, 1911; 3.7 Vitor Fischel, 1916; 3.8 Wallig e Cia, 1920; 3.9 Moinho Chaves, 1920; 3.10 A. J. Renner - Edifício de Fiação de Lã e Tecelagem, 1922; 3.11 Móveis F. Marquardt, 1927; 3.12 Fábrica de Chapéus Kessler, 1929; 3.13 Cervejaria Continental- Edifício da Maltaria, 1932; 3.14 Importadora Americana, 1932; 3.15 A. J. Renner - Edifício da Tecelagem,1934; 3.16 Neugebauer, 1936; 3.17 Moinho Germani, 1939; 3.18 Tecelagem Rio Guayba, 1946; 3.19 Fiação Penteada Renner ,1947; 3.20 Outros - sem identificação cronológica; 4. Considerações Finais; Referências 


\section{INTRODUÇÃO}

Despertando interesse recente, o patrimônio industrial passou a ser objeto de estudo, pesquisa e debate. São locais onde atividades industriais se instalaram em tempo pregresso e por razões diversas os deixaram. Algumas, relocaram-se para áreas onde sejam favorecidas pela competitividade, seja em busca de infraestrutura para escoar a produção, de mão-de-obra especializada e acessível ou visando incentivos tributários atraentes. Outras, simplesmente fecharam as portas devido a obsolescência funcional de seu produto.

A atividade industrial não deixou de existir, houve uma descentralização do setor, uma fuga das regiões dotadas de centralidade das cidades, deixando as antigas instalações para trás. Por vezes, são amplas estruturas com composições arquitetônicas de relevância histórica e representativas de um período. A conservação e restauração passou a ser um desafio, bem como destinar um novo uso adequado às suas proporções e às necessidades da sociedade atual.

Cabe ressaltar que esta herança industrial não está somente atrelada ao espaço físico da cidade, mas também à sua memória urbana. Por vezes conta a história de uma cidade ou região, marca gerações de famílias, adquire relevância para o coletivo por meio de um valor afetivo e simbólico, e está associada a determinadas atividades produtivas de uma época. No que tange o espaço físico urbano, deixa sua marca na terra, em bairros inteiros ou distritos.

$\mathrm{Na}$ cidade de Porto Alegre/RS não ocorreu diferente. A região conhecida como IV Distrito abrigou no passado o setor industrial da cidade. A ampla área era composta pelas fábricas e toda estrutura adjacente necessária ao seu funcionamento, residências, serviços e pequeno comércio, escolas, praças, igrejas, etc.

Sendo assim, identifica-se neste trabalho, o patrimônio de tipologia fabril relevante no IV Distrito de Porto Alegre, o seu estado atual de conservação e o seu potencial de revitalização. Apresenta-se se houve o reuso da estrutura original, mantendo as características da edificação ou descaracterizando-a, se está abandonado ou se foi demolido. Constatando, além da atual conjuntura do patrimônio, os principais tipos de reuso na região, a qualidade das intervenções e as potencialidades não exploradas.

Para este reconhecimento foram utilizados majoritariamente a dissertação de Miranda (2003) - que analisou a evolução do edifício industrial em Porto Alegre de 1870 a 1950 - e documentos disponibilizados pela Equipe do Patrimônio Histórico e Cultural do município de Porto Alegre (EPAHC), como o Inventário do Patrimônio Cultural de Bens Imóveis dos bairros Floresta, Navegantes e São Geraldo, e o atual levantamento das edificações com características fabris contidos neste inventário. Este último foi disponibilizado para consulta, no ano de 2016, em versão anterior a revisão final. Ainda foram realizadas visitas ao local e revisão bibliográfica acerca do tema proposto.

Este artigo é fruto da pesquisa para a dissertação de título 'Requalificação Urbana e Patrimônio Industrial: estudo de intervenções em áreas de herança industrial', sob orientação do Prof. Dr. Luiz Antônio Bolcato Custódio, apresentada em 2017 ao programa de Pós- 
-Graduação - Mestrado em Arquitetura e Urbanismo da UniRitter / Mackenzie.

\title{
2. O PATRIMÔNIO INDUSTRIAL SEGUNDO A CARTA DE NIZHNY TAGIL
}

Com o objetivo de "promover a cooperação internacional na preservação, conservação, investigação, documentação, pesquisa, interpretação, e promover a educação sobre o patrimônio industrial", foi criada em 1978, a organização mundial The International Committee for the Conservation ofthe Industrial Heritage (TICCIH). (TICCIH, 2016).

O TICCIH é reconhecido pelo Conselho Internacional de Monumentos e Sítios (ICOMOS) e consultor em todos os assuntos relacionados com o estudo e preservação do patrimônio industrial. O ICOMOS é uma organização global não-governamental, criada em 1965, dedicada a conservação de monumentos e sítios históricos e conselheira da UNESCO sobre bens culturais a serem adicionadas à lista de Patrimônio Mundial. Dessa forma, a TICCIH aconselha sobre zonas industriais históricas significativas para a lista (TICCIH, 2016).

Em 2003, durante o XII Congresso Internacional realizado na Rússia pelo TICCIH, foi redigida e aprovada a Carta de Nizhny Tagil que evidencia a importância da herança da industrialização. Posteriormente, em 2005, foi apresentada à XV Assembleia Geral do ICOMOS, realizada na China, para ratificação e aprovação da UNESCO (KÜHL, 2008).

A Carta de Nizhny Tagil confirma a premissa de que o patrimônio industrial não é somente a tipologia fabril em si, mas que engloba todos equipamentos e construções de apoio a determinada atividade produtiva, os quais contribuíram para o seu desenvolvimento e permanência, e que possuam relevância, valor:

\begin{abstract}
O património industrial compreende os vestígios da cultura industrial que possuem valor histórico, tecnológico, social, arquitetônico ou científico. Estes vestígios englobam edifícios e maquinaria, oficinas, fábricas, minas e locais de tratamento e de refinação, entrepostos e armazéns, centros de produção, transmissão e utilização de energia, meios de transporte e todas as suas estruturas e infraestruturas [sic], assim como os locais onde se desenvolveram atividades sociais relacionadas com a indústria, tais como habitações, locais de culto ou de educação. (KÜHL, 2008, p.51).
\end{abstract}

\section{A CIDADE DE PORTO ALEGRE E SUA HERANÇA INDUSTRIAL}

O IV Distrito de Porto Alegre está localizado na porção noroeste da cidade e está situado às margens do rio Guaíba. Possui uma ampla área, 594 hectares, e é composto por cinco bairros: Humaitá, Farrapos, Navegantes, São Geraldo e Floresta. Com uma posição estratégica e privilegiada, é vizinho ao bairro Centro Histórico e conecta-se a ele por duas grandes vias internas, a Rua Voluntários da Pátria e a Avenida Farrapos. 


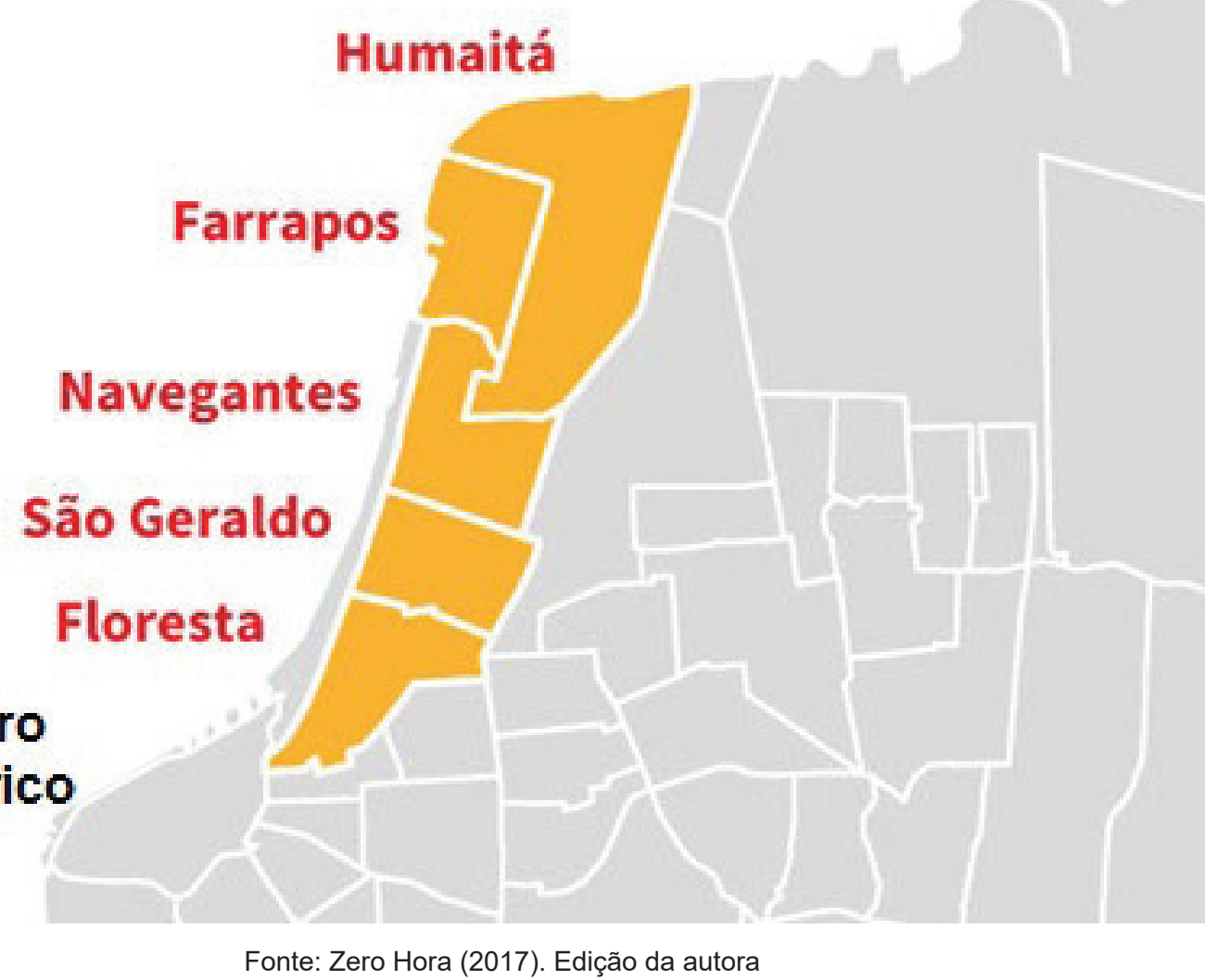

Por meio do levantamento e diagnóstico das principais tipologias com características fabris do IV Distrito de Porto Alegre, observa-se que a grande maioria das indústrias da época locaram-se na rua Voluntários da Pátria. Na testada oposta da mesma via, próximo ao rio, construíram seus galpões de depósitos e trapiches, de modo, assim, a manter proximidade com todo o transporte do entorno, viário, ferroviário e fluvial.

Para identificar o patrimônio industrial do IV Distrito foi realizado um mapeamento, utilizando como base o mapa do Inventário do Patrimônio Cultural de Bens Imóveis dos bairros Navegantes, São Geraldo e Floresta, fornecido pela EPAHC. Posteriormente, organizou-se este patrimônio em ordem cronológica, quando possível. 


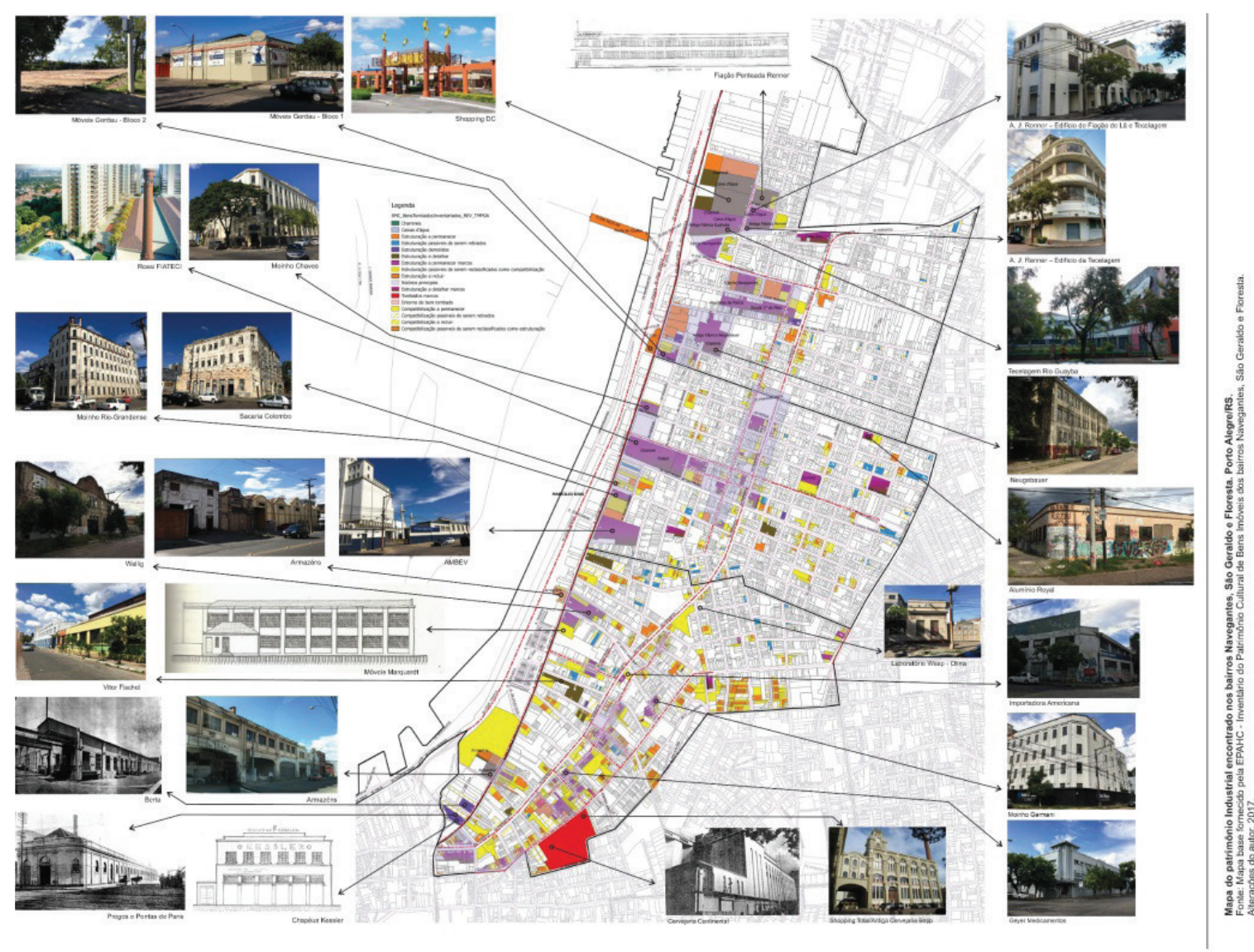

\subsection{BERTA, 1873}

Antiga fábrica Berta foi fundada em 1873 e fabricava cofres, fechaduras, fogões, camas, baldes galvanizados, etc. Em 1910, Adolf Fick foi contratado para ampliação, sendo possivelmente o autor do projeto original. Estima-se que a área construída possuía cerca de $3.200 \mathrm{~m}^{2}$. Localizava-se na rua Voluntários da Pátria, 355, entre as ruas Garibaldi e Ernesto Alves. A edificação foi demolida.

Figura 2: Antiga fábrica Berta

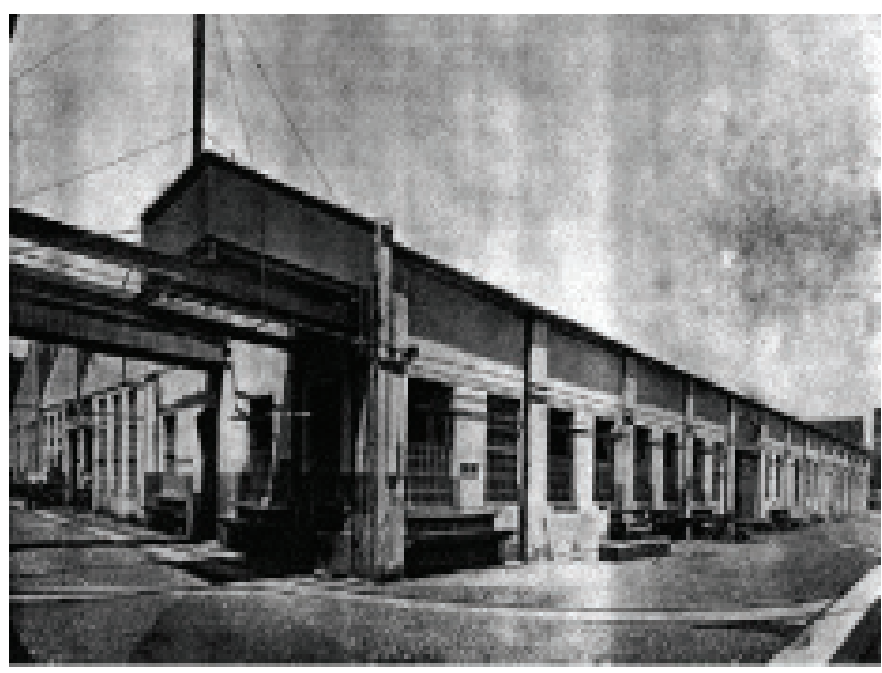

Fonte: Blancato (1922, apud MIRANDA, 2003, p. 72) 


\subsection{PREGOS E PONTAS DE PARIS, 1891}

Antiga fábrica de Pregos e Pontas de Paris foi instalada em 1891 e a partir de 1901 passou a pertencer a família Gerdau. Não se sabe a autoria do projeto e da construção. O bloco único de cerca de 173 metros de comprimento localizava-se na rua Voluntários da Pátria, 140, esquina com rua Garibaldi.

Foi uma das primeiras edificações construídas especificamente para fins industriais na cidade. Permaneceu no local até a década de 1950 e posteriormente cedeu lugar ao antigo Hotel Conceição II. A edificação foi demolida.

Figura 3: Antiga fábrica de Pregos e Pontas de Paris

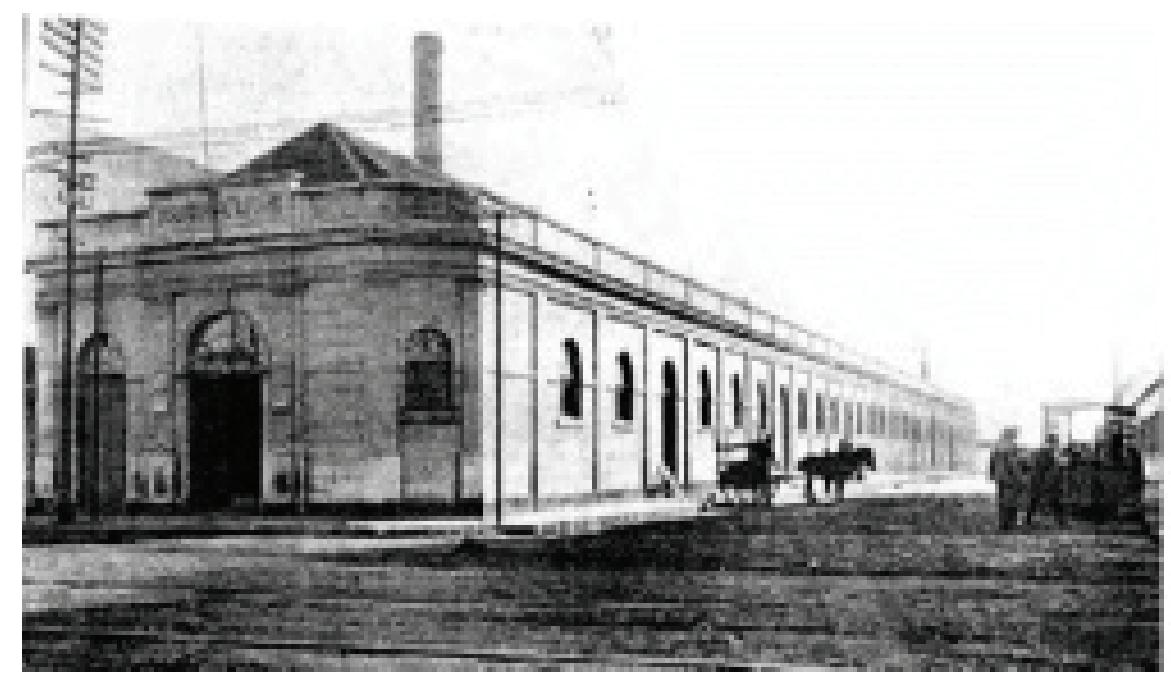

Fonte: Blancato (1922, apud MIRANDA, 2003, p. 68)

\subsection{COMPANHIA FIAÇÃO E TECIDOS PORTO ALEGRENSE - FIATECI, 1891}

Importante fábrica do ramo da tecelagem, a Companhia Fiação e Tecidos Porto Alegrense foi construída em 1891. Sabe-se que a ampliação, realizada em 1924, é de autoria do polonês Jacob L. Pufal, o qual manteve a linguagem dos prédios originais e muito provavelmente é o autor do projeto original. Localiza-se na av. Voluntários da Pátria, esquina com av. São Pedro e ocupa todo o quarteirão, formado pela av. Polônia e rua Santos Dumont.

Atualmente, cede lugar ao empreendimento Rossi FIATECI, da construtora Rossi, com as novas torres finalizadas em 2015. O projeto recicla quatro pavilhões térreos de valor histórico - utilizados para vagas de garagem, lojas, supermercado e memorial - e adiciona quatro novas torres, sendo três residências e uma de escritórios, entregues e ocupadas.

Em termos compositivos os novos blocos em nada dialogam com os pavilhões existentes ou com o entorno. Estes últimos, são descaracterizados com a elevação da cobertura em cerca de meio metro para viabilizar um segundo pavimento de estacionamento. Suas fachadas com ornamentos e aberturas são preservadas apenas no alinhamento da av. São Pedro. A marcante chaminé - importante símbolo fabril - foi também preservada. 
Figuras 4 e 5: Empreendimento Rossi FIATECI, área de estacionamento e futura área comercial, respectivamente. Pavilhões com alteração na altura do telhado
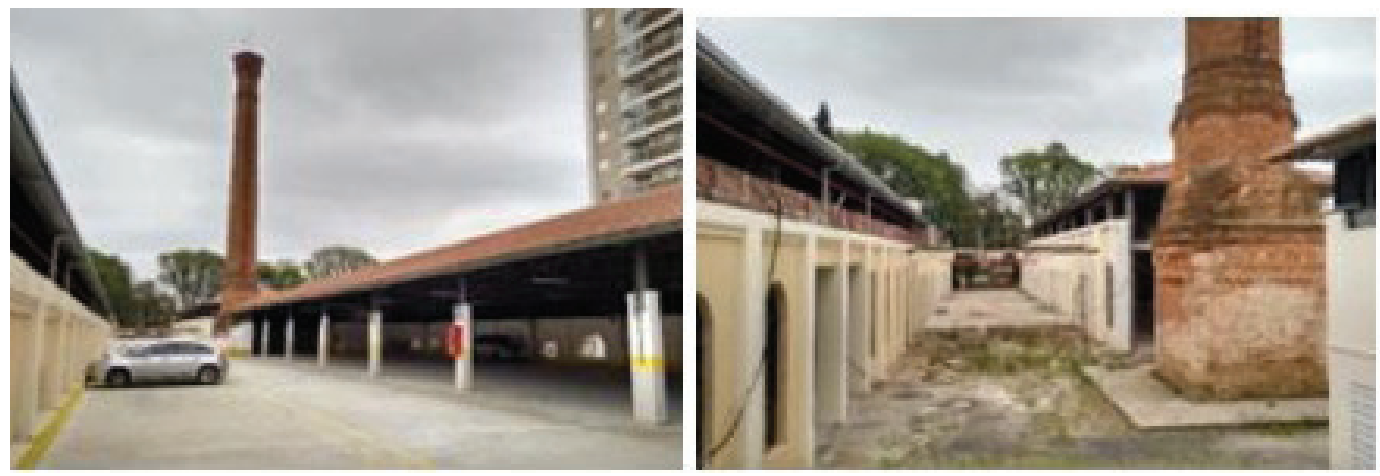

Fonte: Fotografia da autora (2015)

\subsection{CERVEJARIA BOPP, 1910}

Projeto do arquiteto Theo Wiederspahn, datado de 1910, a cervejaria Bopp "[...] tinha claramente a intenção de apresentar a magnitude de sua empresa, primeiramente em razão de suas proporções e, em segundo lugar, pela farta ornamentação das suas fachadas e cúpula." (MIRANDA, 2003, p.81). Na época, foi considerado o maior projeto de concreto armado do país.

Localiza-se na av. Cristóvão Colombo, com fundos para a rua Gonçalo de Carvalho. O complexo constitui o único patrimônio tombado do IV Distrito. Em 1999, foram tombados os prédios da Fabricação, Fermentação, Caldeiras e Escritórios, além da chaminé, estando inscritos no Livro do Tombo sob o n. ${ }^{\circ} 58$.

Com projeto de intervenção do arquiteto Analino Zorzi, inaugurado em 2003, atualmente funciona no local o Shopping Total. A restauração desse patrimônio histórico garantiu sua preservação e trouxe dinâmica a este espaço, com a inserção de lojas, serviços e restaurantes. Regenerou um espaço ocioso desde 1998 e que possui grande valor histórico para a cidade.

\section{Figuras 6 e 7: Fachada do Shopping Total}

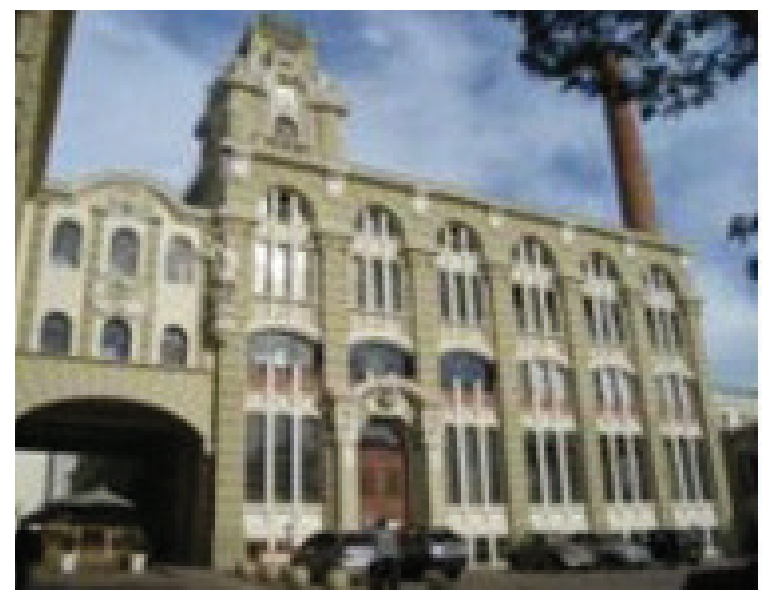

Fonte: Skyscrapercity (2015)

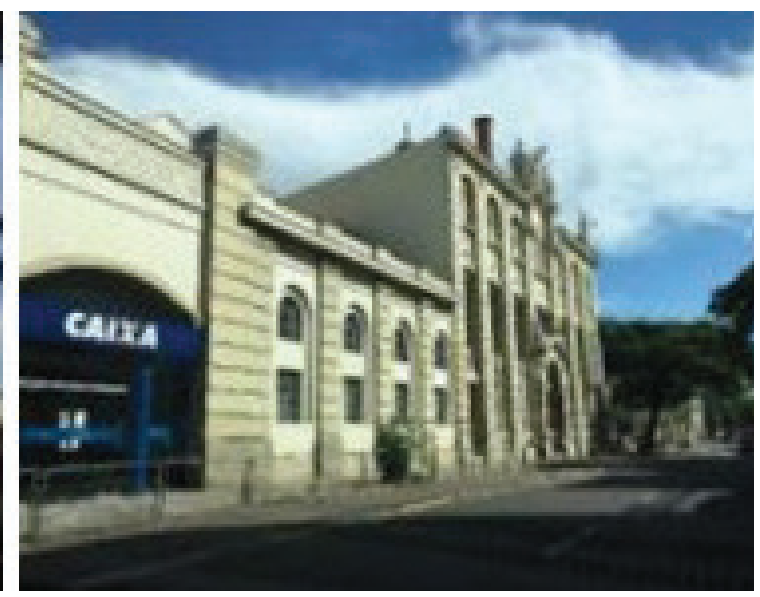

Fotografia da autora (2017) 


\subsection{MOINHO RIO-GRANDENSE, 1915}

O Moinho Rio-Grandense foi construído em 1915, pelo industrial português José Albino Cunha. Projetado por técnicos ingleses Antônio Maria dos Santos. Possui dois blocos, o moinho com $2611 \mathrm{~m}^{2}$ e o depósito com $1348 \mathrm{~m}^{2}$. Segundo Miranda (2003) o moinho é um dos primeiros exemplos locais em altura, com 4 e 5 pavimentos, e apresenta notável simplificação formal e compositiva em relação aos edifícios do período.

Em 1924, o Grupo Bunge e Born o adquiriu e acrescentou um pavimento e uma cobertura com lanternim. Localiza-se na rua. Voluntários da Pátria esquina com rua Moura de Azevedo. Atualmente apresenta-se desocupado e em mau estado de conservação.

Figura 8: Antigo Moinho Rio-Grandense

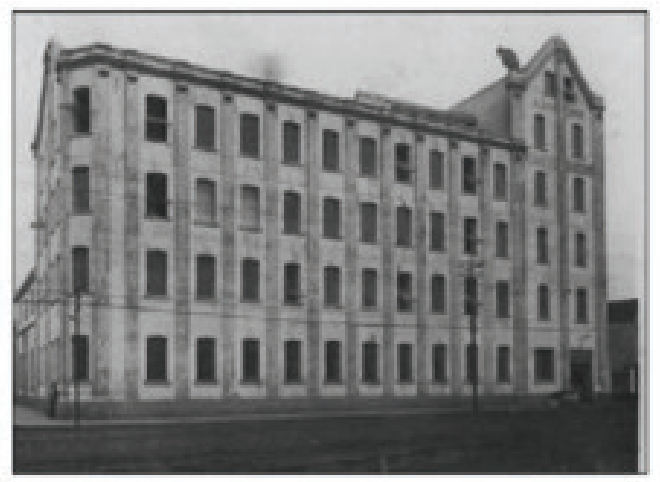

Fonte: Acervo do Centro de Memória Santista (apud MIRANDA, 2003, p. 89 e 91)
Figura 9: Moinho Rio-Grandense atualmente

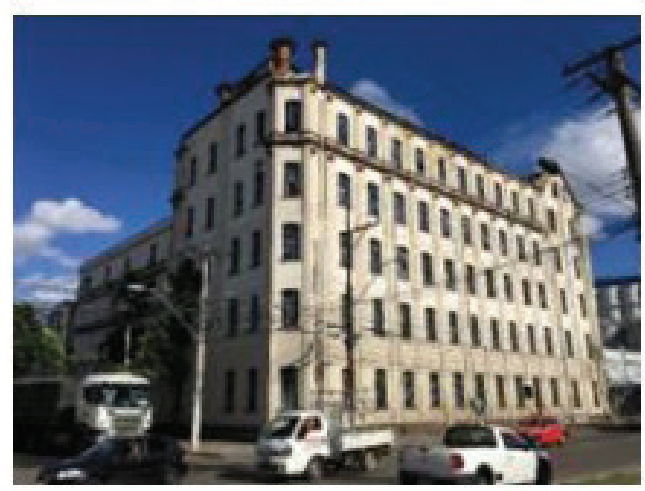

Fonte: Fotografia da autora (2017)

\subsection{MÓVEIS GERDAU, 1911}

A fábrica de móveis Gerdau foi um projeto de Theo Wiederspahn, sendo a construção de Josef Hruby. Localizado na esquina da rua Voluntários da Pátria com a av. Brasil, era composta por dois blocos, um em frente ao outro. Atualmente, no bloco 1 funciona a empresa Guarda Bem, que oferece serviço de armazenagem. O bloco apresenta-se bastante descaracterizado, sendo mantido apenas a sua dimensão original com o chanfro de esquina. Verifica-se que as aberturas foram modificadas, bem como a cobertura. O bloco 2 foi demolido.

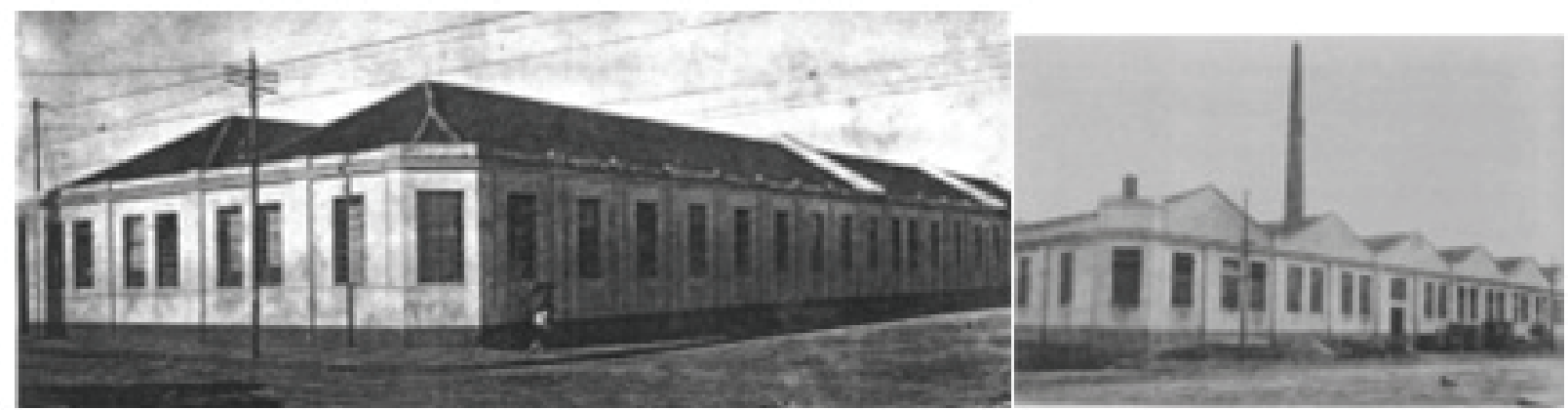

Fonte: Blancato (1922, apud MIRANDA, 2003, p. 76) e Assis (2011, p. 132 apud MIRANDA, 2003, p. 76) 
Figura 12 e 13: Fábrica de móveis Gerdau atualmente, bloco 1 e local onde deveria estar o bloco 2, respectivamente
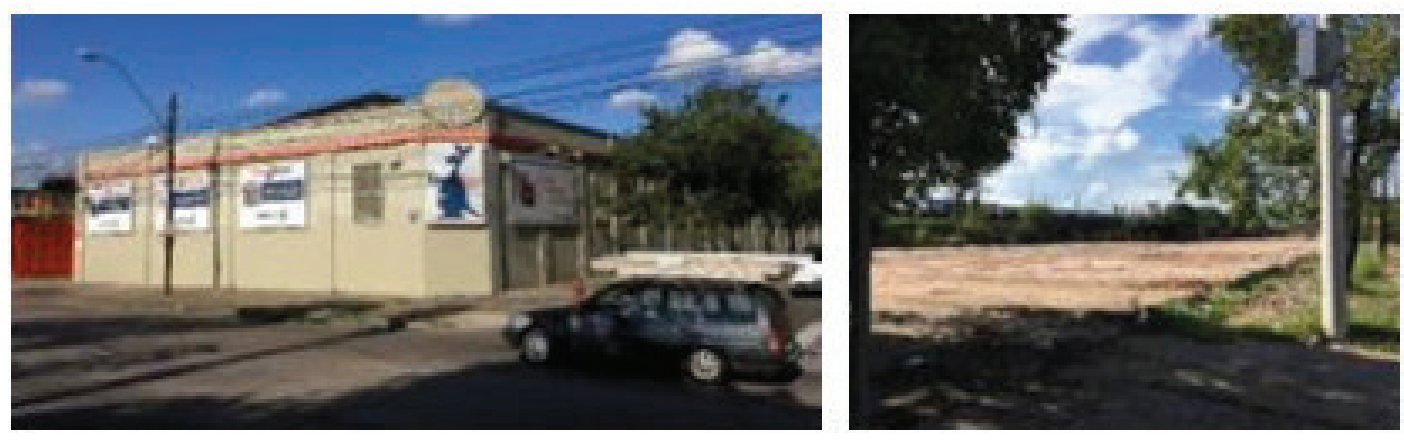

Fonte: Fotografia da autora (2017)

\subsection{VITOR FISCHEL, 1916}

Fábrica de sabão e sabonetes, obra de Hruby. Localizava-se na rua Hoffmann, 67, próxima à av. Voluntários da Pátria, e se expandiu para outros pontos na mesma rua. $\mathrm{A}$ partir de 1916, ocupou também o n. ${ }^{\circ} 23$, e a partir de 1918 o n. ${ }^{\circ} 2$. Edificação encontra-se descaracterizada, sendo atualmente utilizada para armazenagem de lixo reciclado, nas proximidades da Vila dos Papeleiros.

Figura 14: Antiga fábrica Victor Fischel

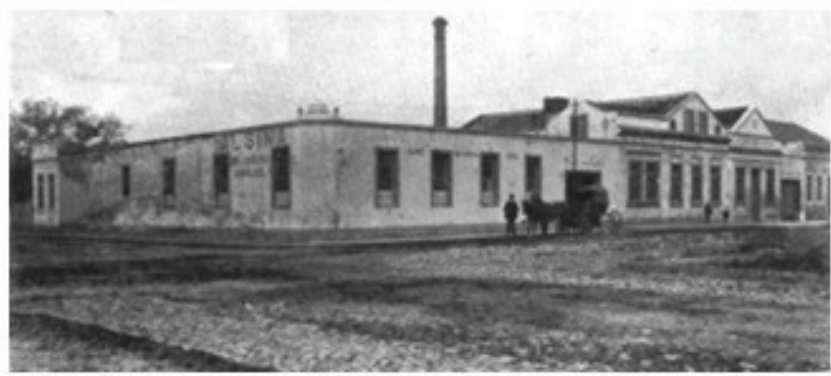

Fonte: UrbsNova (2017)
Figura 15: Vitor Fischel atualmente - rua Hoffmann

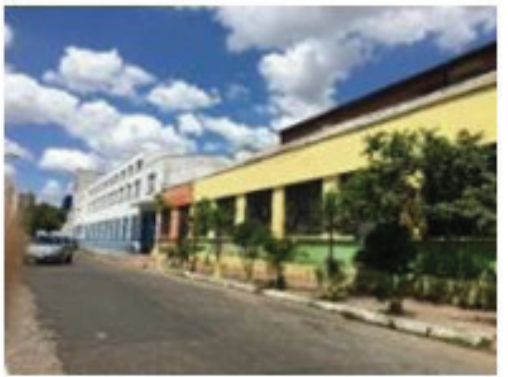

Fonte: Fotografia da autora (2017)

\subsection{WALLIG E CIA, 1920}

O complexo Wallig foi projetado pelo arquiteto Theo Wiederspahn, em 1920. Composto por quatro pavilhões, localiza-se no quarteirão da rua Câncio Gomes (antiga rua Sete de Abril), rua Almirante Barroso, e av. Voluntários da Pátria. Atualmente, o que resta do complexo está descaracterizado e em ruínas.

Figura 16: Perspectiva do complexo Wallig

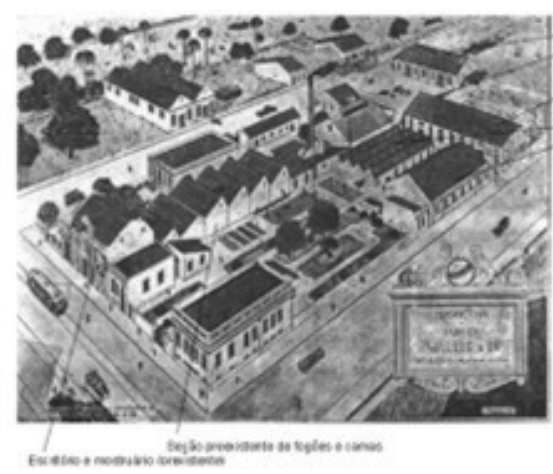

Fonte: Blancato (1922, p.174 apud MIRANDA, 2003)
Figura 17: Ruínas do complexo Wallig na rua Almirante Barroso
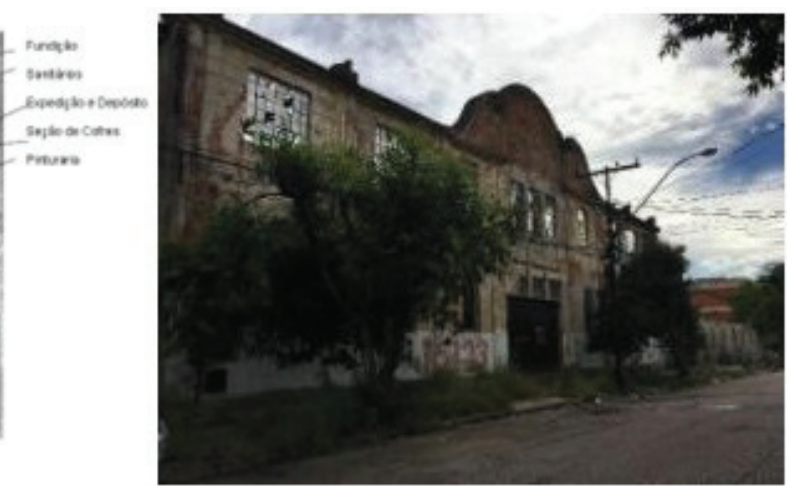

Fonte: Fotografia da autora (2017) 


\subsection{MOINHO CHAVES, 1920}

O Moinho Chaves foi projetado para moagem de trigo, em 1920, por Theo Wiederspahn. Localiza-se na rua Voluntários da Pátria, 3303, esquina com rua Ernesto da Fontoura. Até alguns anos atrás, o prédio serviu de sede comercial para a empresa Ferramentas Gerais. Atualmente, funciona no local o estabelecimento comercial de refrigeração Dufrio e aparenta bom estado de conservação, com manutenção das características principais da fachada, sem uso de adornos.

Figura 18: Antigo Moinho Chaves

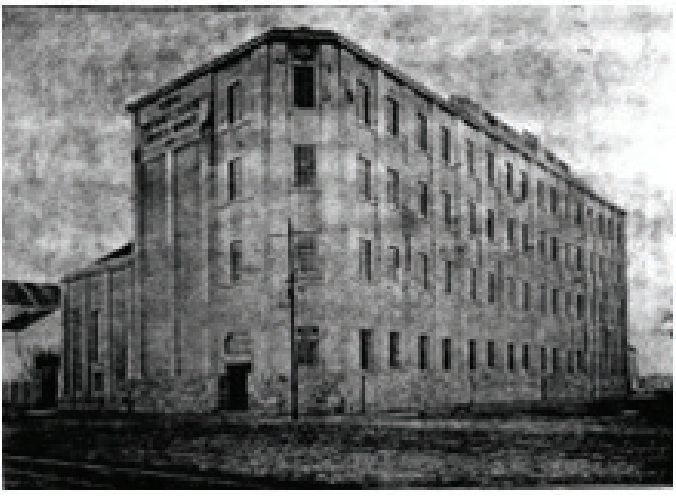

Fonte: Blancato (1922, apud MIRANDA, 2003, p. 102)
Figura 19: Edificação do Moinho Chaves, atualmente

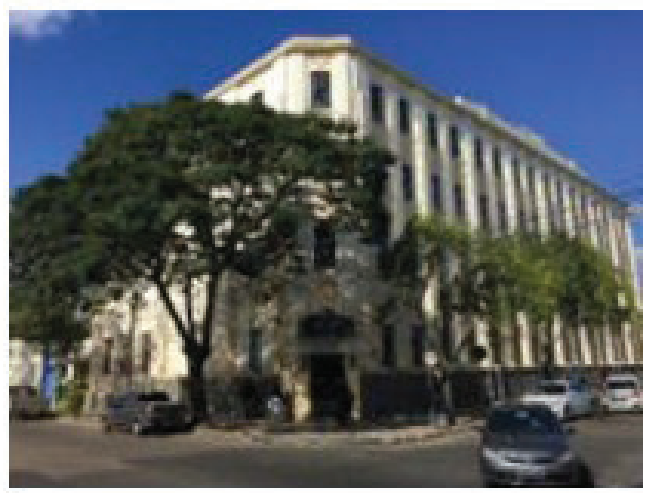

Fonte: Fotografia da autora (2017)

\subsection{A. J. RENNER - EDIFÍCIO DE FIAÇÃO DE LÃ E TECELAGEM, 1922}

Projeto de Carl Hartmann em 1922, devido ao grande aumento da produção da empresa A.J. Renner. Localiza-se nas esquinas da rua Frederico Mentz e travessa São José. Estende-se por ao longo do quarteirão e possui dois acessos marcados por torres de circulação vertical com cúpulas de cobre. Chegou a fazer parte do projeto do DC Navegantes, quando foi parcialmente restaurada. Até alguns anos atrás, uma parte da edificação sediava a universidade IPA. Hoje, está desocupada.

Figura 20: A. J. Renner - Edifício de Fiação de Lã e Tecelagem - atualmente

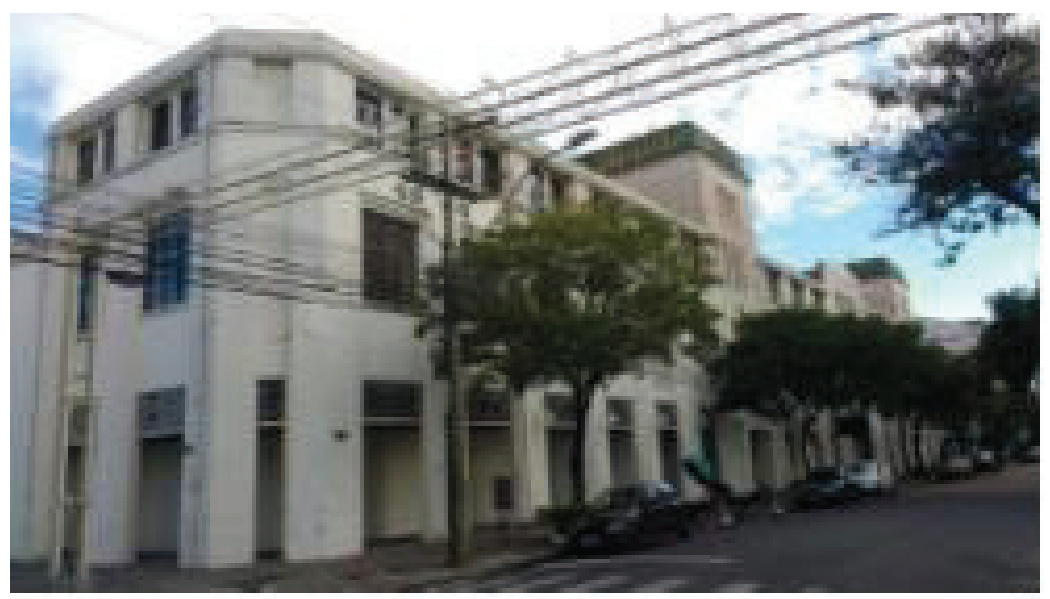

Fonte: Fotografia da autora (2017) 


\subsection{MÓVEIS F. MARQUARDT, 1927}

Projeto atribuído a Carl Friedrich Fick da empresa Fick Irmãos. Hoje demolido, localizava-se na av. Voluntários da Pátria, 417/412, quarteirão das ruas Câncio Gomes e Paraíba.

Figura 21: Fachada Móveis F. Marquardt

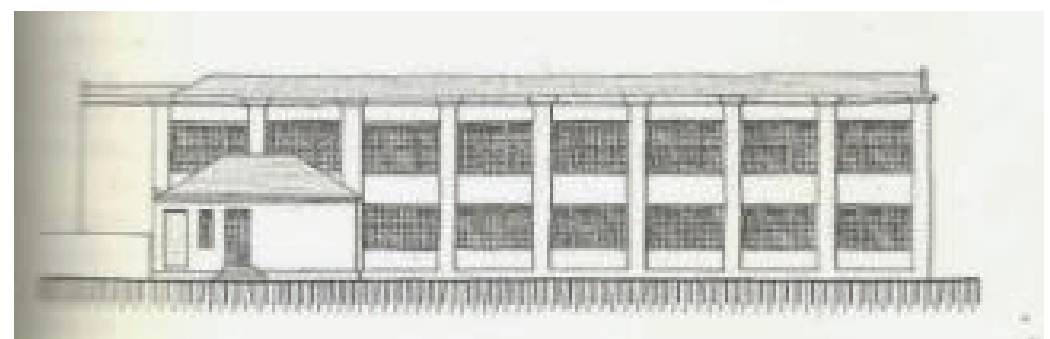

Fonte: Weimer (1998, p. 33)

\subsection{FÁBRICA DE CHAPÉUS KESSLER, 1929}

Projeto do arquiteto Egon Weindorfer, localizava-se na Av. Voluntários da Pátria, entre ruas Garibaldi e Barros Cassal. A edificação não foi encontrada no local, possivelmente foi demolida ou muito descaracterizada, impedindo a identificação.

Figura 22: Fachada da Fábrica de Chapéus Kessler

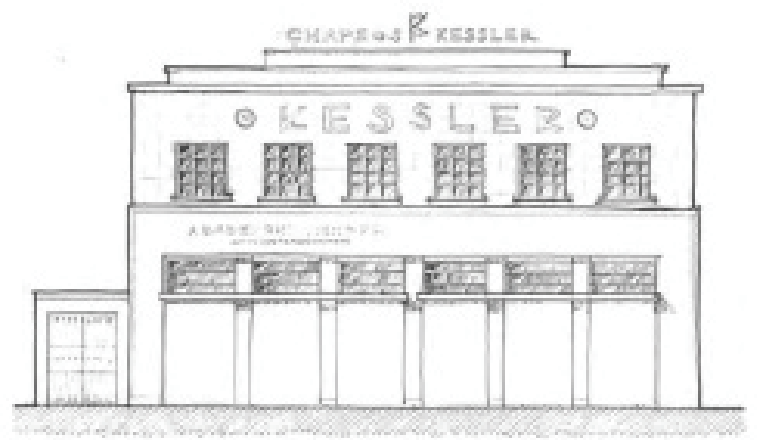

Fonte: Mattar (2001, apud MIRANDA, 2003, p. 114)

\subsection{CERVEJARIA CONTINENTAL- EDIFÍCIO DA MALTARIA, 1932}

Projetado pelo engenheiro Willy Stein, fez parte do complexo da Cervejaria Continental, originada da fusão das cervejarias Bopp, Sassen e Ritter. A maltaria foi demolida.

Figura 23: Fachada da Maltaria Continental

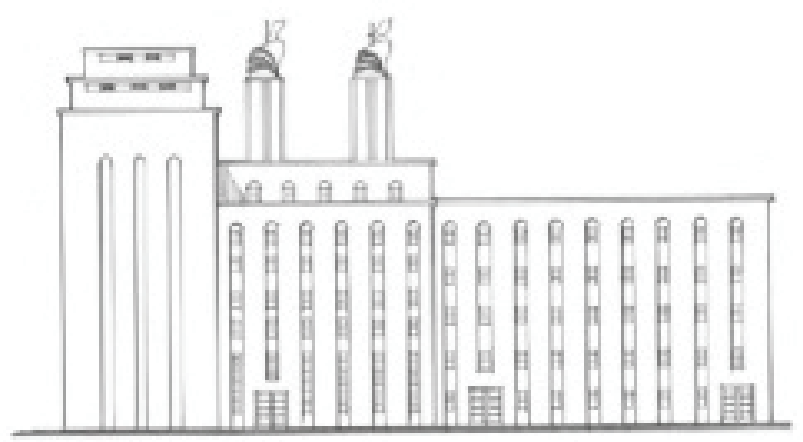

Fonte: Miranda (2003) 


\subsection{IMPORTADORA AMERICANA, 1932}

Não há informações sobre a autoria do projeto. Foi fundada em 1932, para a fabricação de rádios, máquina de costura entre outros produtos. Na década de 60 ingressaram na comercialização de aços. Localiza-se na av. Farrapos, esquina com rua Sete de Abril. Atualmente, está desativada e em estado de ruína.

Figuras 24 e 25: Edificação da antiga Importadora Americana
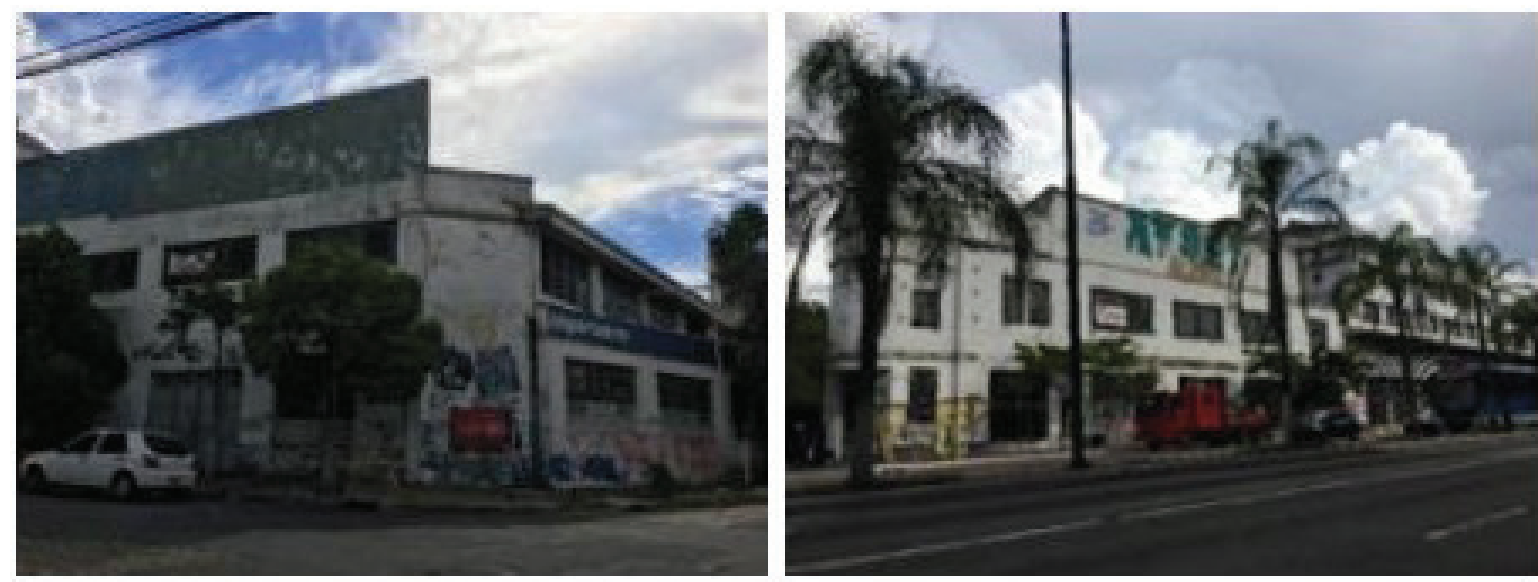

Fonte: Fotografia da autora (2017)

\subsection{A. J. RENNER - EDIFÍCIO DA TECELAGEM,1934}

Projeto do arquiteto Egon Weindorfer e construção da empresa Azevedo Mooura \& Gertum. Na década de 30, o complexo Renner já se estendia por mais de um quarteirão, localizado no bairro Navegantes, executando sucessivas construções para diversificação da produção (MIRANDA, 2003).

Localiza-se nas esquinas das ruas Frederico Mentz e Lauro Muller. Possui fachada curva e geometria trapezoidal. Fez parte do projeto do complexo DC Navegantes. Atualmente, está desocupada.

Figura 26: A. J. Renner - Edifício da Tecelagem Figura 27: Edificação J. Renner- Edifício da Tecelagem, atualmente

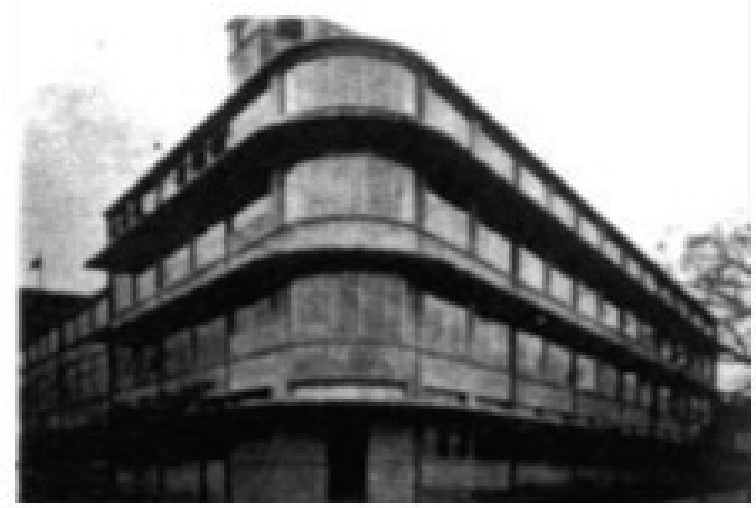

Fonte: Luccas (200, p.25. apud MIRANDA, 2003, p. 127)

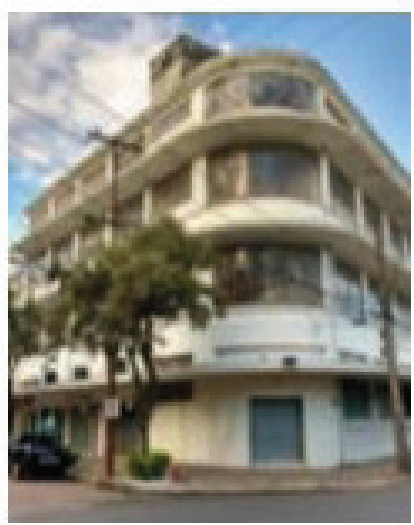

Fonte: Fotografia da autora (2017) 


\subsection{NEUGEBAUER, 1936}

A fábrica de chocolates Neugebauer, a mais antiga de chocolates do Brasil, foi fundada em 1891, no Bairro Navegantes. Em 1903, foi iniciada a construção da sede. A fábrica possuía aproximadamente 700 funcionários, dos quais a grande maioria residia nas proximidades, entre os bairros Navegantes e São Geraldo. Localiza-se na av. Rio Grande esquina com av. Cairú. A fábrica continua no mesmo quarteirão, porém, seu edifício histórico está abandonado.

Figura 28: Complexo fabril Neugebauer, década de 50 Figura 29: Antigo prédio da Neugebauer

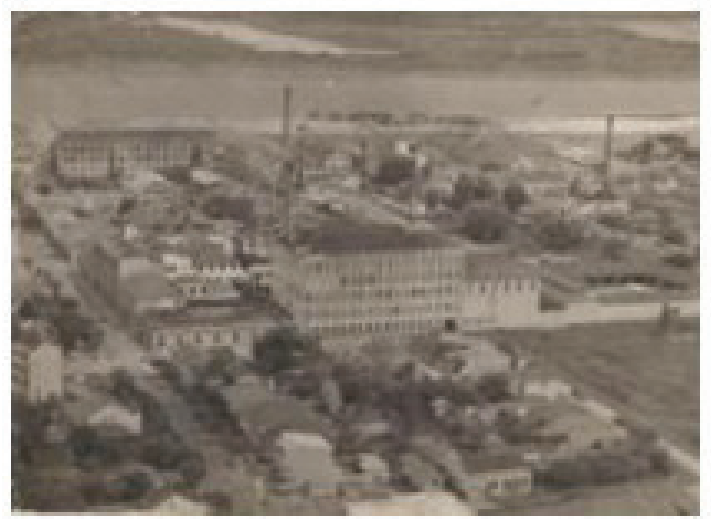

Fonte: Blog Geração Urbana (2014)

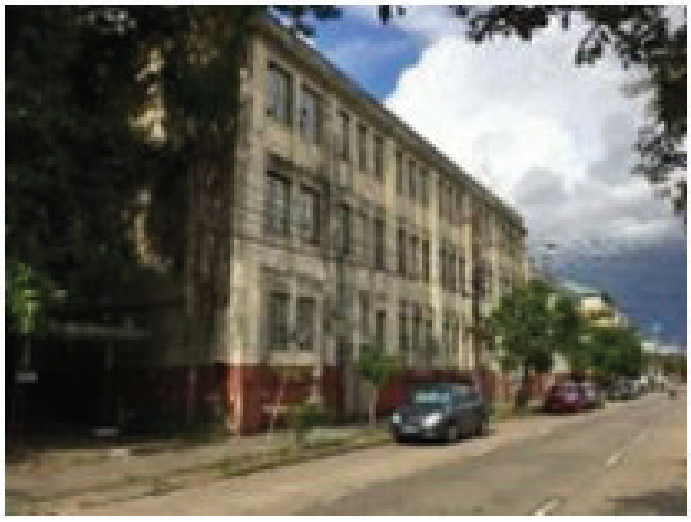

Fonte: Fotografia da autora (2017)

\subsection{MOINHO GERMANI, 1939}

Moinho de trigo, construído pela construtora Azevedo Moura \& Gaertum, é um empreendimento do italiano Aristides Germani. O edifício principal possui área de 4,3mil metros quadrados, estrutura de concreto, laje de madeira e paredes em alvenaria. Localiza-se nas esquinas das ruas Sete de Abril e Emancipação. Em 2010, foi desativado e assim permanece atualmente.

Figura 30: Moinho Germani, atualmente

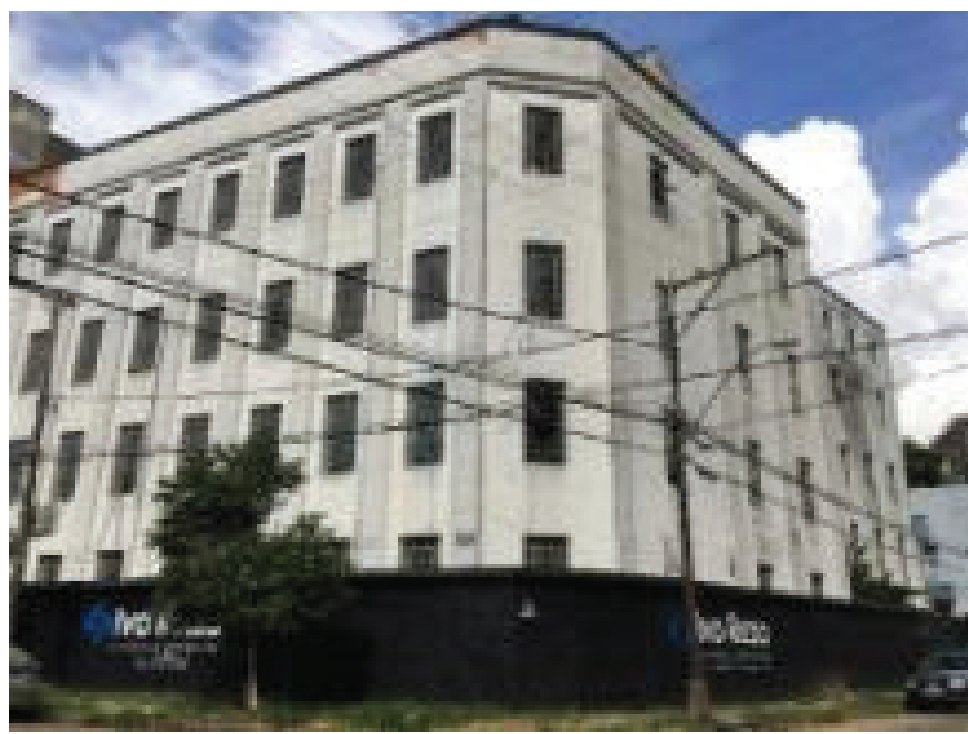

Fonte: Fotografia doa autora (2017) 


\subsection{TECELAGEM RIO GUAYBA, 1946}

Projeto do arquiteto Friedrich Schlander e do construtor Carlos Schuler. Localiza-se na rua Frederico Mentz, 1683, ao lado do atual DC Navegantes. Possui dois blocos paralelos com planta livre e aberturas em fita. Está em estado de abandono e ruína.

Figuras 31 e 32: Antiga Tecelagem Rio Guayba, vista da rua Frederico

Mentz e de dentro do Shopping DC, respectivamente
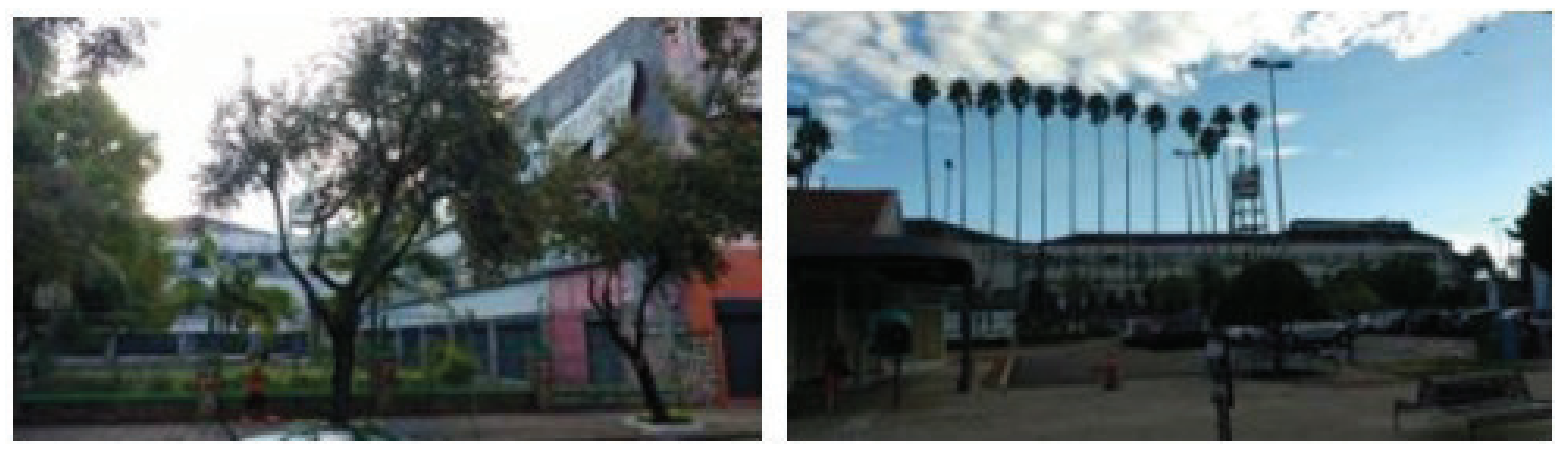

Fonte: Fotografia da autora (2017)

\subsection{FIAÇÃO PENTEADA RENNER ,1947}

Projeto de Eugen Deutrich, mais uma edificação do complexo Renner. É composta de um pavilhão retangular e uma torre anexa. Localizava-se nas esquinas das ruas Frederico Mentz e travessa São José. Não foi localizada.

Figura 33: Fachada da Fiação Penteada Renner

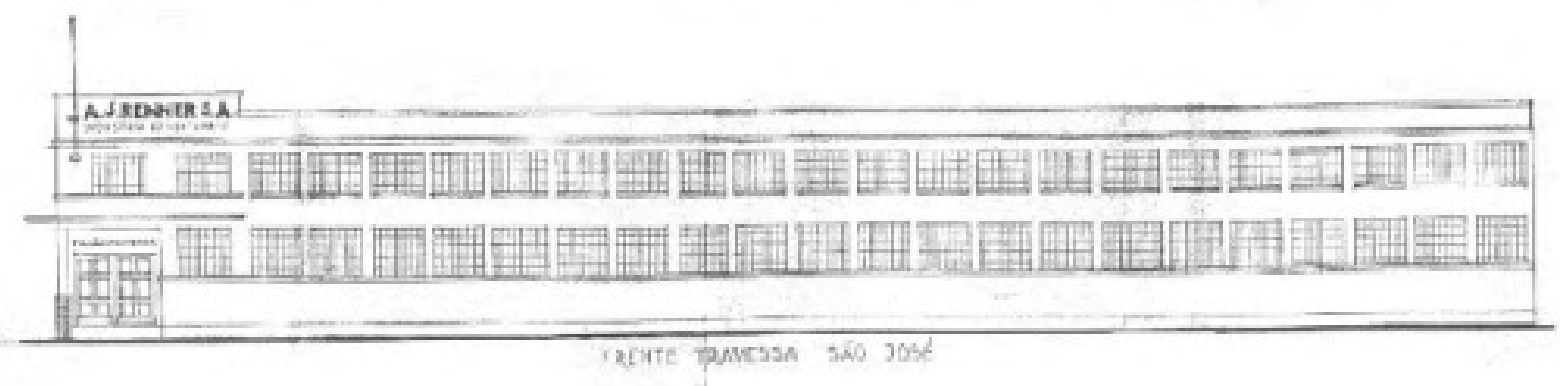

Fonte: Miranda (2003)

\subsection{OUTROS - SEM IDENTIFICAÇÃO CRONOLÓGICA}

Outras edificações de cunho fabril são facilmente identificáveis na região e carecem de informações completas, como autor de projeto e ano de construção. Porém, são significativas no contexto do IV Distrito e algumas detém notório potencial de intervenção devido às suas características arquitetônicas.

Cita-se o caso dos armazéns no alinhamento da av. Voluntários da Pátria, que estão localizados no lado oposto ao das edificações industriais. Eles possuem uma arquitetura marcante, um ritmo contínuo devido ao pé-direito duplo, ou em alguns casos dois pavimentos, e às grandes aberturas no térreo para acesso de caminhões. Por vezes, abrigavam o setor administrativo das indústrias no seu segundo pavimento. No passado, possuíam ligação direta com o rio Guaíba para desembarque e recebimento de mercadorias través de 
seus trapiches anexos.

São dois conjuntos que ainda permanecem na região, uns em melhores condições de conservação que outros. Em sua maioria possuem reuso comercial ou seguem utilizados como depósito.

Figuras 34, 35 e 36: Armazéns na av. Voluntários da Pátria - respectivamente nas imediações das ruas

Ernesto Alves e Comendador Coruja, e Câncio Gomes e Almirante Barroso - em frente à antiga Wallig
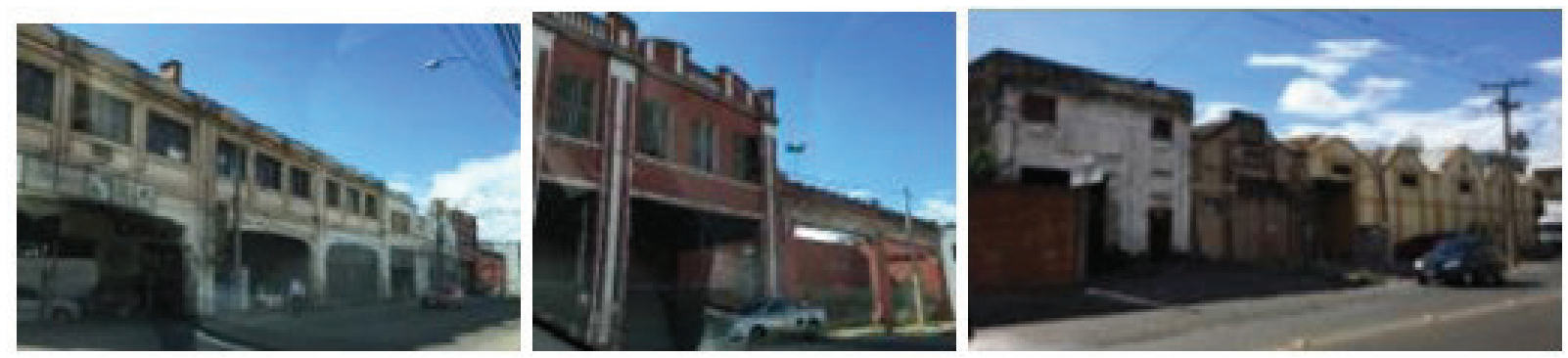

Fonte: Fotografia da autora (2017)

Há edificações que mantêm o mesmo uso para o qual foram construídas, até hoje. É o caso de alguns armazéns acima e da Geyer Medicamentos. Um laboratório farmacêutico, fundado em 1929, que teve sua sede em Porto Alegre inaugurada em 1935. Está localizado na rua Pelotas, 320, esquina com rua São Carlos, e até hoje está em funcionamento no local, mantendo um ótimo estado de conservação da edificação.

Figura 37: Geyer Medicamentos

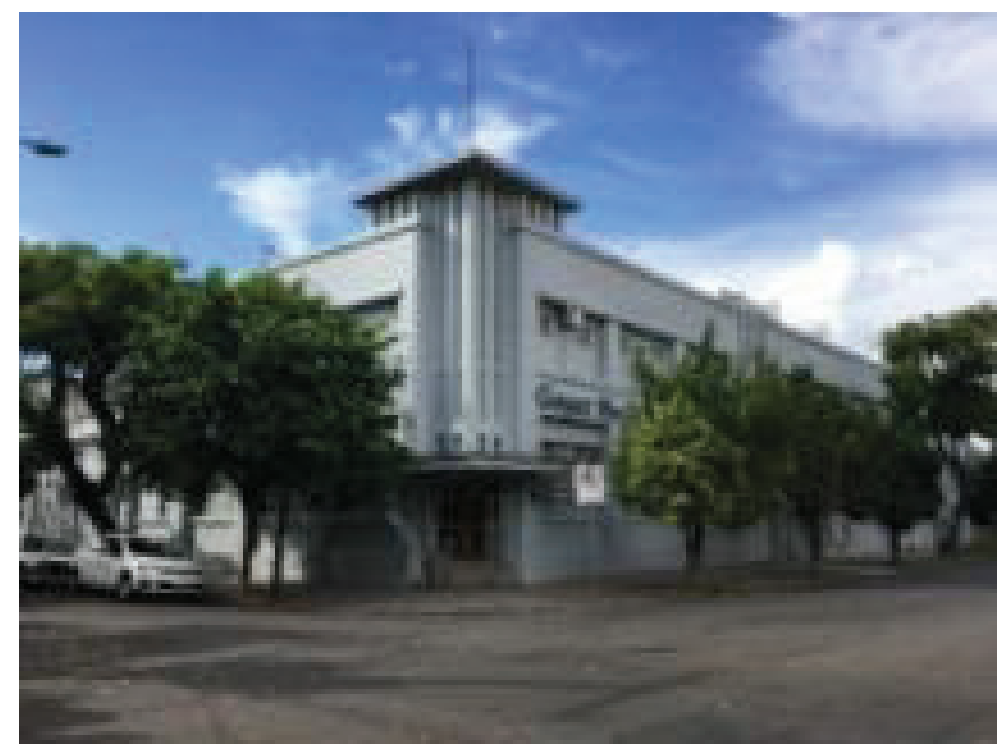

Fonte: Fotografia da autora (2017)

Na rua Conde de Porto Alegre, número 320, está a edificação do Laboratório Wesp, produtor do conhecido medicamento Olina. Fundado em 1916 por João Wesp, imigrante alemão, no mesmo local que está situado até hoje. Inicialmente locado em uma residência e após adquirindo os prédios adjacentes, totalizando hoje $2.400 \mathrm{~m}^{2}$ de área construída. Atualmente, as edificações estão à venda. 
Figura 38 e39:Laboratório Wesp
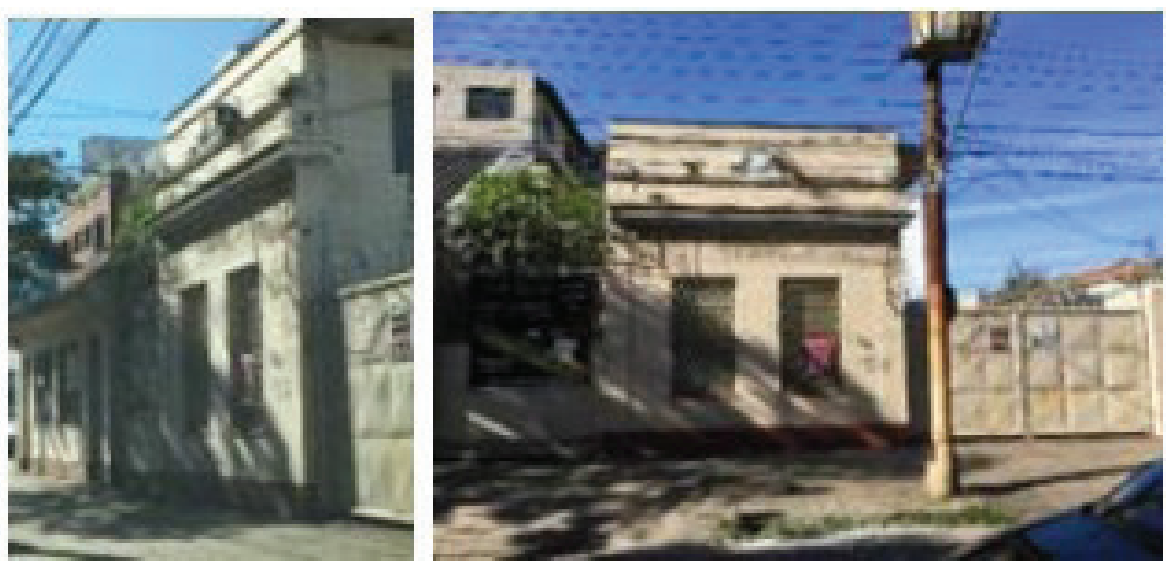

Fonte: Fotografia da autora (2017)

A Sacaria Colombo e a Alumínio Royal são duas edificações relevantes e imponentes por suas dimensões que se encontram em estado ruim de conservação, sendo que uma está em ruína. A Sacaria Colombo está localiza na av. Voluntários da Pátria, 2873, esquina com rua Moura de Azevedo, em frente ao Moinho Rio-Grandense. É uma edificação de grande dimensão, possuindo três andares.

Figura 40: Sacaria Colombo

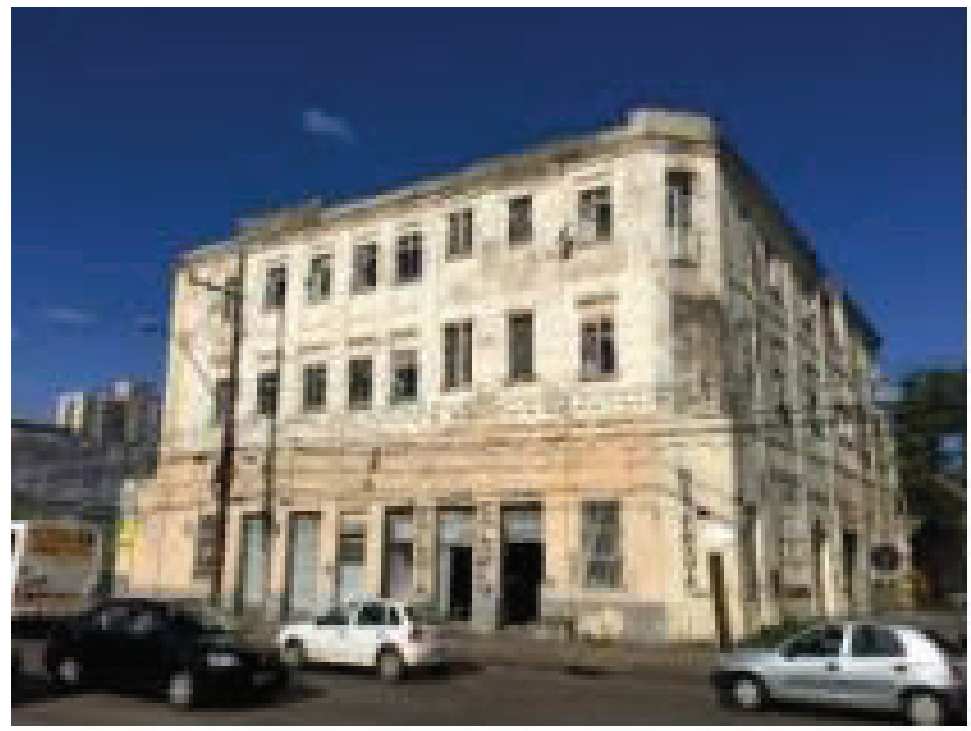

Fonte: Fotografia da autora (2017)

A Alumínio Royal está fora do eixo da av. Voluntários da Pátria, localiza-se nas esquinas das avenidas Brasil e Amazonas. A edificação térrea, distribui-se horizontalmente no vasto terreno de esquina. Está em estado de ruína, sem cobertura ou divisões internas, apenas a casca externa permanece. 

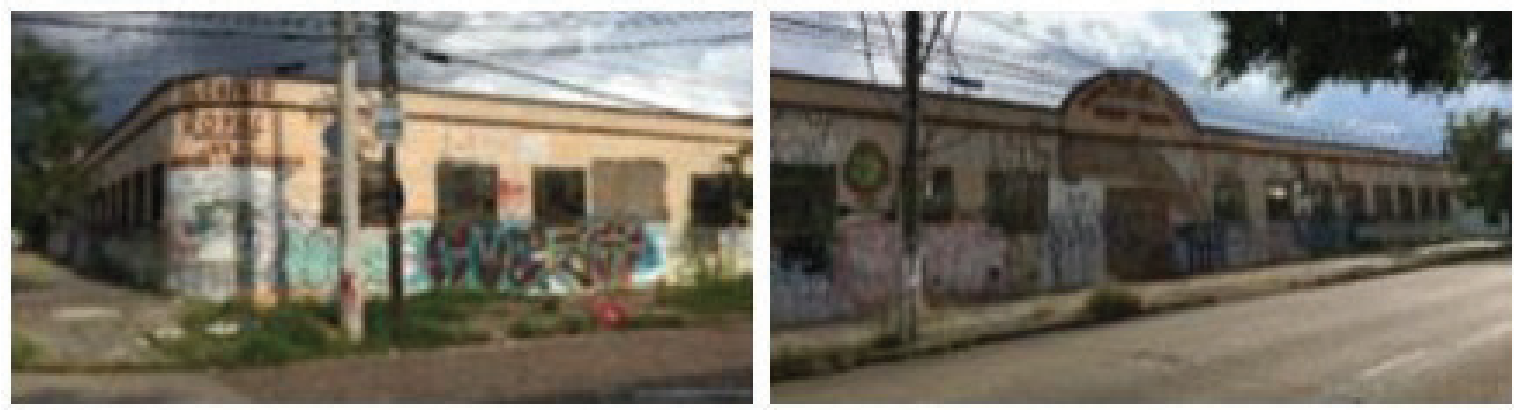

Fonte: Fotografia da autora (2017)

O atual complexo da AMBEV Maltaria Navegantes em funcionamento na av. Voluntários da Pátria, 2619, ocupa o miolo de um quarteirão estendido. Possui acesso por três ruas, sendo uma sem saída. Na rua dos fundos, a Conselheiro Travassos, é possível visualizar o inscrito BRAHMA na fachada. AAmbev nasceu, em 1999, da união entre as centenárias Cervejaria Brahma e Companhia Antarctica. Porém, a história começou muito antes, quando eram duas cervejarias na década de 1880: a Companhia Antarctica Paulista e a Manufactura de Cerveja Brahma \& Villeger \& Companhia.

Figuras 43 e 44: Atual complexo fabril da AMBEV - Antiga Brahma
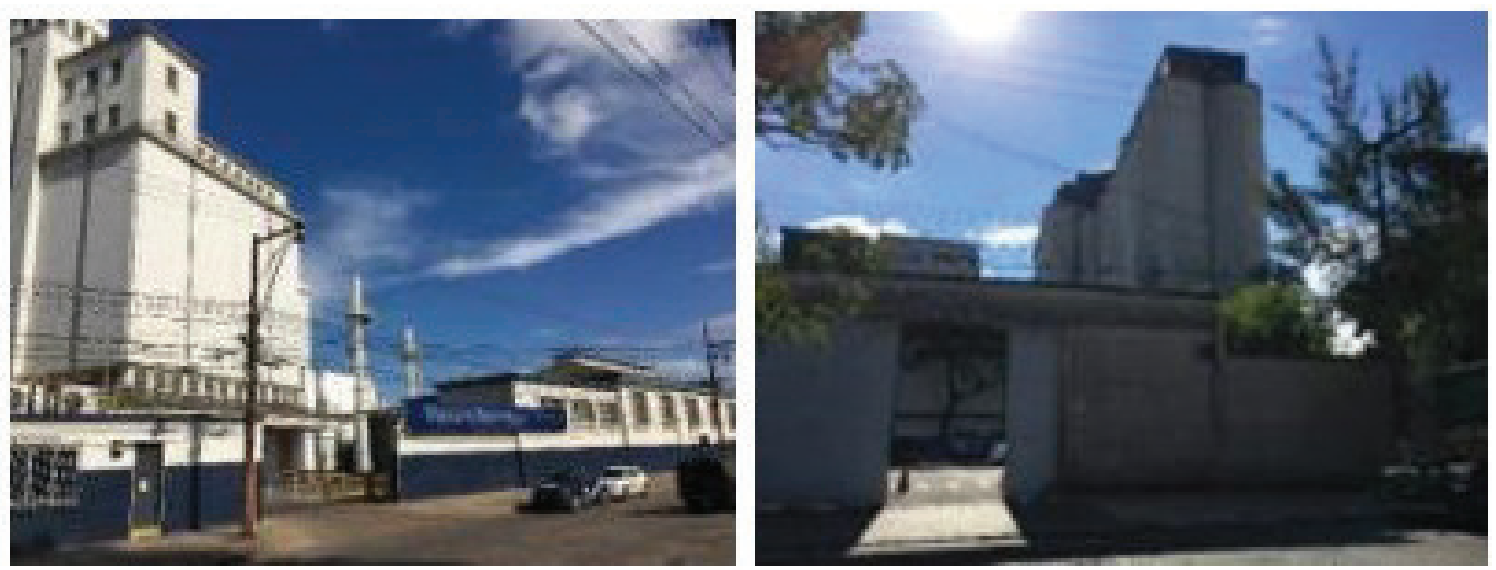

Fonte: Fotografia da autora (2017)

A AMBEV está em funcionamento no mesmo quarteirão que o antigo Moinho Rio-Grandense, evidenciando o caráter ainda fabril da região mesclado ao abandono do patrimônio industrial.

O complexo hoje ocupado pelo DC Shopping, situado entre a av. Voluntários da Pátria e rua Frederico Mentz, foi inaugurado em 1994 e reutiliza antigas edificações da fábrica A.J. Renner. Faz parte de um projeto maior, chamado DC Navegantes, que além do quarteirão hoje ocupado pelo shopping, abrangeu dois quarteirões adjacentes, incluindo as já citas $A$. J. Renner - Edifício de Fiação de Lã e Tecelagem e a A. J. Renner - Edifício de Tecelagem. 


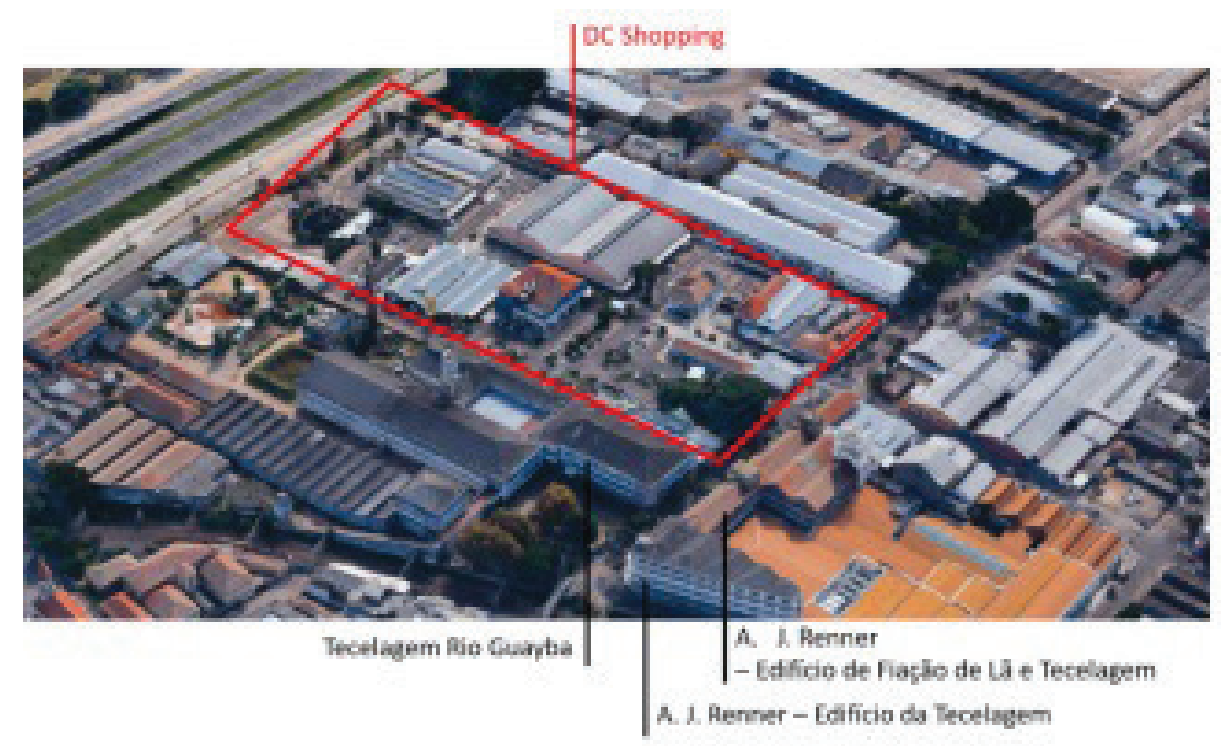

Fonte: Google Maps. Edição da autora (2017)

O projeto é independente e percursor em Porto Alegre. Foi lançado para ser um shopping ao céu aberto, para classe média, com descontos em produtos, ao que seria um espaço de compras do tipo outlet. Atualmente, o shopping abriga majoritariamente lojas de decoração, praça de alimentação, teatro e serviços. As edificações A. J. Renner - Edifício de Fiação de Lã e Tecelagem e a A. J. Renner - Edifício de Tecelagem foram inicialmente restauradas, mas hoje estão desocupadas.

\section{CONSIDERAÇÕES FINAIS}

A mudança é a natureza da existência, estamos condicionados a mudança desde sempre. Para Ascher (2010), o mesmo acontece com a cidade, que não é estática, mas formada por um grupo de pessoas que coexistem em um mesmo espaço e o modificam: "a dinâmica da urbanização está ligada ao potencial de interação oferecido pelas cidades, à sua 'urbanidade', ou seja, à potência multiforme que gera o reagrupamento de uma grande quantidade de pessoas em um mesmo lugar." (ASCHER, 2010, p.19).

Como aliar as mudanças da sociedade e da economia aos bens culturalmente significativos, parece ser uma das chaves para a sua preservação. Ou seja, de que maneira intervir nesses espaços adequando-os às novas necessidades da atividade humana e reconectá-los à malha urbana?

Reinserir o patrimônio industrial na cidade contemporânea implica necessariamente em atribuir um novo uso para esse local, por meio de uma ação planejada, ou por vezes, da apropriação espontânea da comunidade. Objetivando assim, "costurar novamente esse projeto, esse retalho da cidade, na trama urbana- e, ao mesmo tempo, fortalecer toda a trama ao redor." (JACOBS, 2011, p. 437).

Atualmente, a cidade de Porto Alegre e seu antigo distrito industrial possuem três intervenções - não articuladas entre si - significativas no seu patrimônio industrial com a finalidade de viabilizar o seu reuso. São elas: o Shopping DC, o Shopping Total e o empreen- 
dimento Rossi FIATECI.

Considera-se, a priori, que não existe rearquitetura sem modificação. No caso do FIATECI, o telhado dos pavilhões foi elevado para permitir o novo uso e as torres foram erguidas para financiar o restauro do patrimônio e, assim, viabilizar o empreendimento economicamente. Cabe uma crítica à qualidade da arquitetura dos blocos novos, mas não o questionamento de sua existência.

O Shopping Total (antiga Cervejaria Bopp) e o Shopping DC (antigo complexo Renner) possuem usos similares, reunindo em um mesmo espaço comércio e serviços. O primeiro está em um ambiente fechado, com localização favorecida e fazendo uso de um patrimônio tombado. A sua fachada apresenta-se altamente ornamentada, sendo, por si só, um convite a conhecer o lugar. Já, o segundo carece de tamanho privilégio locacional, sendo que seu entorno, ainda com muitos prédios abandonados, transparece o descaso com o patrimônio industrial. Embora possua dois acessos - um deles com ligação direta ao restante da cidade - ainda parece estar escondido no contexto urbano e mesmo dotado de infraestrutura tem ares de periferia.

Dos três moinhos identificados, no IV Distrito, apenas o Moinho Chaves apresenta reuso - de cunho comercial - e preservação da estrutura original. Os outros dois, Moinho Rio-Grandense e Moinho Germani, estão desativados e abandonados. Este último, embora com excelente localização, próximo a av. Cristóvão Colombo, uma consolidada via repleta de estabelecimentos comerciais, apresenta sua enorme estrutura vazia, em franca decadência e com um enorme potencial.

Poucas são as indústrias que permanecem no IV Distrito. Merece destaque a AMBEV Maltaria Navegantes, que se apropria da estrutura da antiga BRAHMA. O grande complexo da Neugebauer hoje reduzido, mas ainda em funcionamento no mesmo local, acabou por abandonar seu prédio histórico. Imagina-se que sua manutenção se tornou onerosa frente a construção de novas edificações.

Observa-se que cerca de 6 edificações, do levantamento, já foram totalmente demolidas e outros vários estão em estado de ruína. Porto Alegre urge por intervenções articuladas e rápidas. $O$ patrimônio existente apresenta grande potencial de intervenção e inúmeras são as possibilidades.

Para a viabilização do patrimônio industrial da cidade de Porto Alegre é notória a necessidade de ações e projetos articulados, que envolvam o conjunto como um todo. Quando se fala em conjunto, refere-se tanto a um projeto que costure o patrimônio industrial novamente à cidade, como ações que envolvam a esfera pública e privada numa troca de interesses. Gerando assim, novos lugares viáveis economicamente e atrativos a um uso sequente.

\section{REFERÊNCIAS}

ASCHER, F. Os Novos Princípios do Urbanismo. São Paulo: Romano Guerra, 2010.

BLOG GERAÇÃO URBANA. A Fábrica de Chocolate do $4^{\circ}$ Distrito. 2014. Disponível em: https:// 
geracaourbanapoa.wordpress.com/2014/04/21/a-fabrica-de-chocolates-do-4o-distrito/. Acesso em: 10 dez. 2016.

BOLG URBSNOVA. Josef Hrubý: um arquiteto tcheco em Porto Alegre. 2013. Disponível em: https:// urbsnova.wordpress.com/tag/fabrica-de-moveis-gerdau/. Acesso em: 10 jan. 2017.

JACOBS, J. Morte e Vida de Grandes Cidades. São Paulo: Martins Fontes, 2011.

KÜHL, B. M. Preservação do patrimônio arquitetônico da industrialização: problemas teóricos do restauro. São Paulo: Atêlie Editorial, 2008.

MIRANDA, A. E. A evolução do edifício industrial em Porto Alegre 1870 a 1950. Porto Alegre: UFRGS, 2003. Dissertação de mestrado - Programa de Pesquisa e Pós-Graduação em Arquitetura, Universidade Federal do Rio Grande do Sul, Porto Alegre, 2003.

PORTO Alegre - 156 fotos, dados históricos e muita..muita arquitetura. Skyscrapercity, Porto Alegre, 8 mar. 2007. Fóruns. Disponível em: http://www.skyscrapercity.com/showthread.php?t=532624. Acesso em: 25 jun. 2015.

REFORMULAÇÃO do $4^{\circ}$ Distrito em Porto Alegre prevê mais moradores. Zero Hora, Porto Alegre, fev. 2017. Notícia. Disponível em: http://zh.clicrbs.com.br/rs/porto-alegre/noticia/2017/02/reformulacao-do-4distrito-em-porto-alegre-preve-mais-moradores-9718822.html.

TICCIH. 2016. Disponível em: http://ticcih.org. Acesso em: 21 ago. 2016.

Recebido em: 15/06/2019

Aceito em: 08/07/2019 